\title{
FINANCIAL STRESS IN THE CZECH REPUBLIC: MEASUREMENT AND EFFECTS ON THE REAL ECONOMY
}

\author{
Ján Malega, Roman Horváth*
}

\begin{abstract}
We estimate a financial stress index for the Czech Republic and examine its development during the 2002-2014 period. We find a marked increase in financial stress at the beginning of the global financial crisis with a decrease to nearly pre-crisis levels by the end of our study period. Next, we estimate vector autoregression models of the Czech economy and find that financial stress has systematic effects on output, prices and interest rates, with the maximum response occurring approximately one and a half years after the shock. Specifically, an increase in financial stress is associated with higher unemployment, lower prices and lower interest rates, indicating its detrimental effects on the real economy.
\end{abstract}

Keywords: financial stress indicator, vector autoregression, Czech Republic JEL Classification: E44, E47, G17

\section{Introduction}

In response to the global financial crisis, national and international policy institutions started more intensive monitoring of the soundness of the financial system analysing the potential impacts of financial stress on the economy, and implementing a number of policy measures. Due to the depth and consequences of the crisis, many supervisory authorities have begun to consider a new set of techniques designed to measure the potential vulnerability of financial institutions. In particular, a strong emphasis has been placed on research regarding the development of tools measuring risk and uncertainty as well as their ability to serve as early warning indicators (Vermeulen et al., 2015).

The financial crisis uncovered significant deficiencies in the current stress testing framework calibration (Blaschke et al., 2001). According to Borio et al. (2010), many of these stress testing scenarios were not sufficiently adverse, and therefore providing a false sense of security. Although stress tests are currently a standard tool for many institutions, they are not designed to serve as early warning indicators.

In this article, we aim to calculate a measure of financial instability in the form of a financial stress indicator for the Czech Republic. It measures the level of financial stress by incorporating all the available information in a given period and aggregating them into a single index value. Advantages of this approach include simplicity, easy interpretation and ability to tailor it to the specific conditions of a given economy (Grimaldi,

* Ján Malega, Institute of Economic Studies, Charles University, Prague, Czech Republic (malega. jan@gmail.com);

Roman Horváth, Institute of Economic Studies, Charles University, Prague, Czech Republic and UTIA, Czech Academy of Sciences, Prague, Czech Republic (roman.horvath@gmail.com).

The authors appreciate the support provided from the Grant Agency of the Czech Republic under Grant No. GA15-10331S. 
2010). Sinenko et al. (2013) created a financial stress index (FSI) particularly for Latvia, whereas Cardarelli et al. (2011) developed a FSI to analyse periods of financial stress in 17 advanced economies. Currently, several private institutions also use FSIs to measure stress, for example, Bloomberg and the OECD, which publishes a composite indicator of economic activities for its members.

The focus of this article is therefore to analyse economic environment along with various internationally applied methodologies to select potential variables based on current research, including those unexplored in previous research and to aggregate them into a financial stress index. The motivation is to create an indicator that is particularly suited to the case of the Czech Republic and, with its help, to precisely identify periods of financial distress. Furthermore, we estimate vector autoregression models to examine the systematic relations between financial stress and the real economy to understand the speed and magnitude of the effects of financial stress.

Our results suggest that financial stress increased rapidly at the beginning of the global financial crisis (in 2008) with a relatively rapid return to pre-crisis levels afterwards. Our vector autoregression estimates suggest that financial stress has systematic effects on the real economy. We find that higher financial stress increases unemployment and decreases both prices and interest rates. Our results suggest that the maximum impact of financial stress on the real economy occurs approximately one and a half years after the shock.

This article is organised as follows. Section 2 provides a literature review and description of aggregation methods. We introduce the underlying variables for constructing the financial stress index and the data in Section 3. We present the results in Section 4. Conclusions follow in Section 5.

\section{Literature Review}

The recent financial crisis led to the creation of macroprudential policies designed to safeguard financial stability with a focus on reducing the risk of instability in the system as a whole. Financial stress measures have been developed to assess the current degree of financial imbalance. Holló et al. (2012) describe financial stress as a level of systemic risk that has already materialized. According to Hakkio and Keeton (2009), the main sources of financial stress are increases in financial risk, volatility and spreads between financial assets that may cause further decreases in market prices and liquidity and thus disrupt the normal functioning of financial markets.

\subsection{Financial stress indexes}

One of the earliest financial stress indexes was created by Illing and Liu (2006) to assess the Canadian financial system. They compared nine different indicators weighted according to a given sector's share in the economy. This study was extended by Oet et al. (2011) by applying different weighting methods to create the Cleveland Financial Stress Index. Grimaldi (2010) applied a logit model to extract information incorporated into aggregated indicators. The threshold level was set according to a list of stressful events to create a benchmark. Cardarelli et al. (2011) altered the concept by implementing binary variables expressing states of crisis in 17 advanced economies. Another approach was proposed by Jakubík and Teplý (2011) to assess the financial stability of the Czech corporate sector. It was based on a financial scoring model using corporate accounting data for Czech companies. 
Holló et al. (2012) created the Composite Indicator of Systemic Stress (CISS) to place more weight on situations where financial stress spreads were higher across the entire financial system at the same time. CISS is based on five sub-indexes representing five market segments, which are created from fifteen individual variables aggregated by a quantile transformation function.

Like Holló et al. (2012), Sinenko et al. (2013) divided the financial system into several sectors and assigned few indicators for each sector to assess financial stress and compare three different aggregation methods for Latvia, and Šimáček (2012) did so for the Czech Republic and Hungary. To differentiate this article from Šimáček (2012), we use somewhat different underlying variables to create our financial stress index. In addition, we estimate vector autoregression models to examine the effects of financial stress on the real economy.

Geršl and Heřmánek (2006) proposed the Banking Stability Index for the Czech Republic, an index based mainly on balance sheet data comprising nine variables. The majority of them also serve as financial soundness indicators, as proposed by the International Monetary Fund. According to Moghadam and Viñals (2012), there is still room to refine the analysis of risk identification concerning financial stability in the Czech Republic. They especially mention contagion risks, where better stress tests may improve access to information about whether current capital and liquidity buffers are sufficient or whether additional intervention is needed.

\subsection{Aggregation methods}

The aggregation methods used to develop a financial stress index are nearly as important as the underlying variables. Three aggregation methods are typically used for comparison during the construction of a financial stress index: equal variance weights, methods based on quantile transformation and cumulative distribution function, and principal component analysis.

The method of equal variance assigns equal variance or risk weighting, which ensures that each underlying variable included in the index is equally important. The first step is that all data are standardized and all underlying variables are aggregated into one index by arithmetic mean for a given period:

$$
F S I_{t}=\sum_{j=1}^{n} \frac{\left(X_{j, t}-\overline{X_{j}}\right)}{\sigma\left(X_{j}\right)}
$$

where $X_{j, t}$ is a non-standardized value of indicator $j$ in time $t, \bar{X}_{J}$ is a sample mean, $\sigma\left(X_{j}\right)$ is a sample standard deviation. $F S I_{t}$ is an aggregated value of the financial stress index in period $t$. The disadvantage is that the mean and standard deviation are, by construction, calculated for the whole sample, which makes this approach sensitive to the inclusion of new information. However, it can serve as a useful benchmark for the two other methods.

The second method is based on quantile transformation and the cumulative distribution function, which is relatively more robust compared to the previous method. It tries to remove the sensitivity of the sample mean and sample variance to outliers. It was used by Holló et al. (2012) and Sinenko (2013). The methodology involves creating a cumulative density function $C D F\left(X_{i, j}\right)$ for each indicator $j$. The variable values are sorted in ascending order with the values ranging from 0 to 1 . Once all the indicators have ranks assigned, the CDFs are computed by dividing the rank of each variable by its number of observations 
in a given sample, transforming them into percentiles. This value reflects the probability that given variable reaches a value less than or equal to the current value. The higher the percentile, the more severe the stress event it represents (Sinenko et al., 2013).

$$
C D F(X)=\frac{1}{m} \sum_{j=1}^{n} I\left(X_{i, j} \leq X\right) \text { where } I\left(X_{i, j} \leq X\right)=\left\{\begin{array}{l}
1, \text { if } X_{i, j} \leq X \\
0, \text { if } X_{i, j}>X
\end{array}\right.
$$

The final index is then again produced by arithmetic mean of the transformed variables and then standardized. The main disadvantage of this method is that it does not take into account the absolute difference in values among the variables, just their order.

Principal component analysis is a statistical technique that reveals the relationships in the data and transforms variables into a smaller number of components, thus reducing the dimensionality of the data space. Under the assumption that each variable is sensitive to financial stress, and if financial stress is one of the main factors responsible for the observed correlations among variables, then it can be identified as a principal component. ${ }^{1}$

In line with Cevik et al. (2013), we take only the first principal component. Moreover, we believe that including multiple components, that are later averaged, introduces unwanted noise into our data. In our case, the first principal component represents $41.5 \%$ of the total variance in our data. ${ }^{2}$ An advantage of this method is that it helps separate variables with minimal loss of information. ${ }^{3}$

\section{Construction of the Financial Stress Index - Underlying Variables}

The construction of a financial stress indicator is a complex task with many methodologies developed to identify financial stress. The index itself is a snapshot of the present state of the financial sector defined in such a way that rising levels reflect increasing financial stress. We try to reflect vulnerabilities in the four main part of the financial sector (banking, foreign exchange, debt and equity) to create an index based on a new set of variables.

Our selection of the underlying variables follows, to some extent, traditional indicators used in papers internationally, such as Illing and Liu (2006), Grimaldi (2010), Oet et al. (2011), Islami and Kurz-Kim (2013). Clearly, the variables are also chosen based on data availability. However, we performed significant adjustments to address issues with short-time series. In total, we selected 7 individual indicators.

\subsection{Banking}

Credit gap: The deviation of credit from its trend values (a credit gap) is a convenient measure of periods of distress in the financial sector. As a proxy for credit, we use total loans and receivables provided to clients. In order to determine how credit growth in the economy

\footnotetext{
$1 \quad$ Similar methodology was applied by Illing and Liu (2006) or Stock and Watson (1989).

2 Principal component analysis is computed on standardized data.

3 A prerequisite for applying principal component analysis is a sufficient correlation among the variables in a dataset, which can be assessed by Kaiser-Meyer-Olkin (KMO) test statistics. In our case, the overall value of the KMO statistics is 0.66 , which is more than sufficient to undertake principal component analysis.
} 
is positioned, we apply the Hodrick-Prescott (HP) filter ${ }^{4}$ to capture its trend. An important feature of this indicator is that it tends to increase quickly before stress events take place; therefore, it performs very well in determining downturn periods (Borio et al., 2010). The trend is obtained by the HP filter method using a smoothing parameter lambda. We use $\lambda=14,400$ which is the commonly used value in literature. To acquire the risk component from the data, we examine the difference between the credit level and its HP trend.

Liquidity: Following Islami and Kurz-Kim (2013), we use the spread between the 3M PRIBOR and the interest rate set by the Czech National Bank - CZEONIA - as our liquidity indicator. The PRIBOR quoted for 3 months expresses the short-term costs of bank lending on the interbank market, whereas CZEONIA is a weighted average of the interest rates of all unsecured overnight deposits by other banks. This indicator is a reasonable measure of liquidity stress in the interbank market because, during a downturn period when market liquidity is endangered, the spread between these two rates increases because of flight to quality or credit risk (Oet et al., 2011).

Volatility of the yield curve: We use the difference between the $10 \mathrm{Y}$ Treasury bond yield and the short-term CZEONIA rate. We assume that during a non-stress period, the spread is relatively stable, while during financial stress it tends to change increasing the volatility. This indicator expresses uncertainty in the development of interest rates, and therefore, it represents a threat to the profitability of financial institutions. We use simple historical volatility as a measure. ${ }^{5}$

\subsection{Foreign exchange}

Exchange rate volatility: In order to capture contagion effects via the exchange rate, we use the weighted historical volatility of the EUR/CZK and USD/CZK exchange rates. The weights for EUR and USD exchange rates are identical and are based on the average volume of total foreign exchange market turnover with these currencies in past years. Adam and Benecká (2013) use weights of 0.6 and 0.4, respectively, but changing the weights in this direction did not affect the results significantly.

\subsection{Debt}

10-year Czech Government Bond and German Bund spread: High interest rates on government debt may crowd out the effects of fiscal policy on the economy and subsequently increase financial stress (Louzis and Vouldis, 2013). The German Bund, or the long-term German bond, is commonly used as a benchmark because of its low credit risk premium and liquidity; moreover, the Czech economy is closely linked to Germany. Specifically, the spread between the 10-year Czech Government Bond and German Bund rates expresses market uncertainty, liquidity and the country's creditworthiness. In general, boom periods are accompanied by lower spreads, while periods of financial stress are characterized by quickly widening spreads. Therefore, spreads are convenient tools for measuring the current state of the economy (Borio et al., 2010).

$4 \quad$ For further information about the methodology, see Hodrick and Prescott (1997).

5 An additional underlying variable capturing risk in the banking sector may be the ratio of nonperforming loans to total loans. However, this asset quality indicator is backward looking and does not typically capture future risk well. An alternative in the form of loan loss provisions is not used because of data availability. 
External debt: In emerging market economies, net external debt is important for maintaining sustainable growth. However, excessive debt is perceived to have devastating effects on future economic growth. In the recent literature, external debt is often considered a potential leading indicator of financial stress, especially in developing countries (Aizenman and Pasricha, 2012). We assume that fast growth in external debt is perceived as risky. To extract the stress component, similar methodology was used as in the above mentioned credit gap indicator.

\subsection{Equity}

Stock market volatility: PX index is the official price index of the Prague Stock Exchange, and it represents a sound measure of the profitability of the share market in the Czech Republic. Therefore, we decided to include the volatility of the PX index as one of our underlying variables. We assume that higher volatility represents higher risk and estimate the conditional volatility using a GARCH $(1,1)$ model. The main reason is that it suitably accounts for volatility clustering, which is typical of stock markets.

The main source of our macroeconomic and financial data is ARAD, the public database of the Czech National Banks. The data on 10Y German bonds yield are obtained from the European Central Bank Financial Data Warehouse. Additionally, data for the PX index are acquired from the Prague Stock Exchange website. To not to lose any information, data were not seasonally adjusted. Our underlying data and resulting financial stress index are at the monthly frequency covering the period between February 2002 and February 2014.

The aggregation methods of how we translate underlying variables into final index are described in the Sub-Section 2.2.

\section{Empirical Results}

In this section, we first present our financial stress index for the Czech Republic. Second, we estimate vector autoregression models of the Czech economy and examine the effects of financial stress on the real economy.

\subsection{Financial Stress Index}

In Figure 1 we present the estimated financial stress index values for the Czech Republic. We apply three aggregation methods: Equal Variance, Cumulative Density Function and Principal Component Analysis. Overall, different aggregation methods convey the same message even though the values differ somewhat around the fall of Lehman Brothers in October 2008. According to our results, the most intense period of stress occurred in 2008, although we also observed mild increase in stress in late 2011 and the first half of 2012. In addition, we observed the lowest values of stress in 2007 before the outbreak of the financial crisis. The Czech economy had been growing rapidly before the crisis, inflation was typically not far from the inflation target, and the financial sector had been considered largely stable.

6 External debt indicator is available only at a quarterly frequency; therefore, we interpolated monthly data using cubic spline interpolation, as in Cevik et al. (2013). 


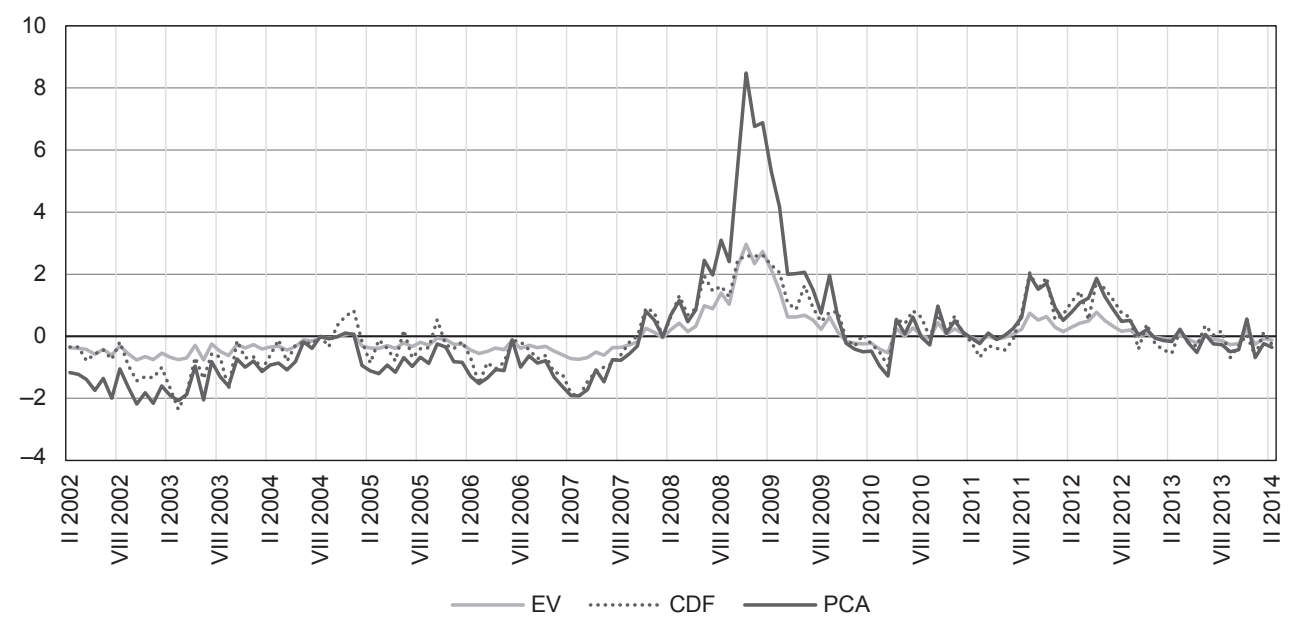

Note: EV represents equal variance aggregation; CDF cumulative density function; and PCA principal component analysis.

Source: Own estimation.

The difference of PCA method compared to other two indexes during late 2008 is caused by the extreme stock market volatility (PX index) during that time. PCA gives a higher importance to observations with higher volatility. For this reason, when examining the effect of financial stress on macroeconomy (see the next sub-section) within the vector autoregression model, we check whether the results depend on the choice of financial stress index. As we show below, the results remain unchanged no matter which index we use.

The correlation among all three indexes is quite high (at minimum 0.88), thus it is not so surprising that the impulse responses give us similar results. This finding largely corresponds to Illing and Liu (2006), who find a limited effect of different aggregating methods on the resulting indexes. However, due to the space limitation, we present the vector autoregression results only with the index the analysis performed on PCA approach and other VAR results are available upon request.

Babecký et al. (2014) develop a database of banking, debt and currency crises for 40 EU and OECD countries over the 1970-2010 period. According to their results, there was no banking, debt or currency crisis in the Czech Republic during the 2000-2014 period. It is worth mentioning that their findings are broadly consistent with our results.

\subsection{Does financial stress have an effect on the real economy?}

Previous research suggests that financial variables or financial stress have systematic effects on the real economy and that financial variables interact strongly. For instance, Hakkio and Keeton (2009) found that an increase in financial stress resulted in more prudent behaviour of credit institutions and a decrease in total loans granted, which consequently slowed economic activity in the United States. Havránek et al. (2012) examined links between financial variables and the macroeconomy using block-restriction autoregression models based largely on pre-crisis data for a different set of variables rather than a financial stress 
index. Cardarelli et al. (2011), in their research, showed that financial stress is not always a predecessor of financial instability, and Li and St-Amant (2010) found that effects of monetary shocks on economy differ depending on the intensity of financial stress. Estimating a VAR model using our newly developed financial stress index is also important to examine whether the index conveys useful information and, therefore, to indirectly determine whether the index values are sensible.

In our article, we use VAR to examine the effects of financial stress on the macroeconomic environment in the Czech Republic. Our general specification, assuming that the economy is described by a structural $\operatorname{VAR}(p)$ model that is of a linear, stochastic dynamic form (omitting the constant), is the following (Lütkepohl, 2005):

$$
Y_{t}=A Y_{t-1}+U_{t}
$$

where

$$
\begin{aligned}
Y_{t}:= & {\left[\begin{array}{c}
y_{t} \\
y_{t-1} \\
\vdots \\
y_{t-p+1}
\end{array}\right], A:=\left[\begin{array}{cccc}
A_{1} & \ldots & A_{p-1} & A_{p} \\
I_{k} & \ldots & 0 & 0 \\
\vdots & \ddots & \vdots & \vdots \\
0 & \ldots & I_{k} & 0
\end{array}\right] U_{t}:=\left[\begin{array}{c}
u_{t} \\
0 \\
\vdots \\
0
\end{array}\right] } \\
(K p \times 1) & (K p \times K p)
\end{aligned}
$$

Errors $U_{t}$ are usually correlated, therefore, errors are orthogonalized by Cholesky decomposition $^{7}$ making the covariance matrix of resulting innovations diagonal.

We use four variables in our VAR system and order them as follows: unemployment, inflation rate, interest rates, and financial stress index. ${ }^{8}$ This specification is broadly in line with previous research, such as Borys et al. (2009) or Havránek et al. (2012). ${ }^{9}$ The ordering is typical of studies that examine macroeconomic variables and order the variables, which do not react contemporaneously to shocks from other variables in the system (Stock and Watson, 2001). For example, our ordering implies that we assume that unemployment does not react contemporaneously to shocks from the interest rates but not vice versa.

We assess the stability of our VAR systems based on characteristic roots of inverse polynomial. VAR system is stable if absolute value of all roots (then number of lags times the number of variables) is less than one. Formally $y_{t}$ is stable if ${ }^{10}$

$7 \quad$ Commonly used in literature, see e.g. Holló et al. (2012).

8 Unemployment is expressed as the general rate of unemployment for those between the ages of 15 and 64 years. Inflation rate is calculated as the percentage rate of change of a consumer price index over previous year. As a measure of interest rates, we use the 3M PRIBOR published by the Czech National Bank.

9 We did not include GDP as a macroeconomic variable in our baseline specification because it is available on a quarterly basis only. Unlike GDP, unemployment is available monthly. GDP would have to be transformed into monthly series using some filtering technique. Industrial production is available monthly but the share of industry is approximately $38 \%$ of GDP in the Czech Republic. Nevertheless, we conduct robustness check, where we use GDP growth instead of unemployment in the VAR estimation.

10 See Lütkepohl (2005) Chapter 2.1.1. 


$$
\operatorname{det}\left(I_{k}-A_{1} z-\ldots-A_{p} z^{P}\right) \neq 0 \text { for }|s| \leq 1
$$

We find our VAR system stable; therefore, we estimate the VAR in levels and do not transform it into the first differences. In line with the suggestions of Sims et al. (1990), we do not impose possible cointegration relations explicitly. Based on lag length exclusion tests and information criteria, we choose two lags for our VAR. These results are available upon request.

Figure 2 | Financial Stress and the Real Economy in the Czech Republic: Impulse Responses

Response of INF to Cholesky

One S. D. FSI Innovation

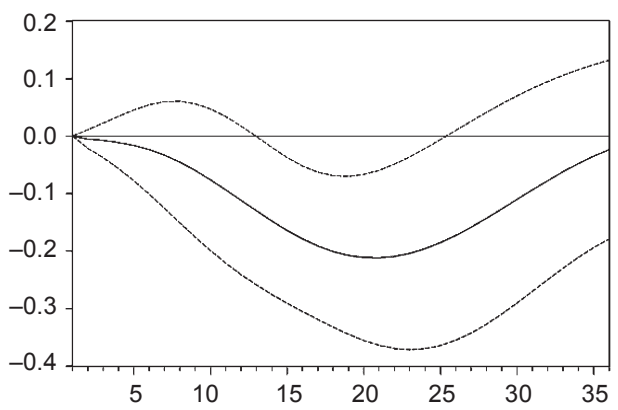

Response of IR to Cholesky

One S. D. FSI Innovation

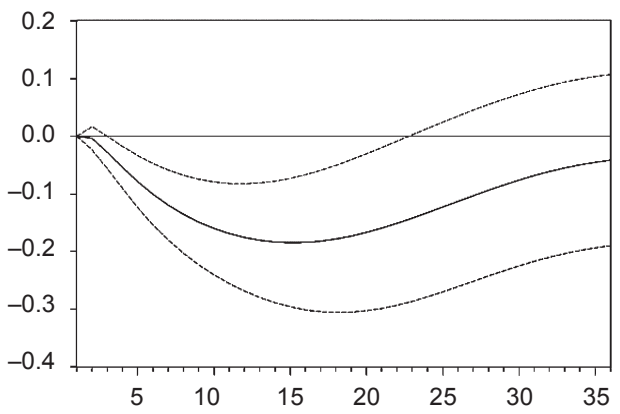

Response of UNEM to Cholesky One S. D. FSI Innovation

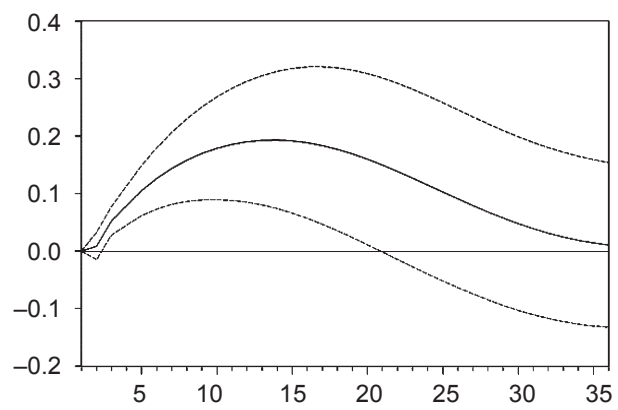

Note: FSI stands for financial stress index; UNEM for unemployment; INF for inflation; and IR for interest rates. The $\mathrm{X}$-axis is in months $95 \%$ confidence intervals.

Source: Own estimation.

We present the impulse response between the financial stress index based on the principal components as the aggregation method and the real economy in Figure 3. We find that unemployment increases following unexpected increases in financial stress. The strongest effect occurs approximately one and a half years after the shock, which is broadly in line with the results presented by Havránek et al. (2012).

Next, our results suggest that prices decline during times of elevated financial stress. These results show that there are significant interactions between price stability and financial stability (Horváth, 2009). For example, good historical evidence of that relationship is 
the notable decrease in inflation after Q4 2008, when the financial stress associated with the recession was culminating in the Czech economy. The maximum reaction of prices to financial stress appears to occur approximately two years after the shock.

Finally, we examine the reactions of short-term interest rates to financial stress. We find that higher financial stress is associated with lower interest rates. This negative response of interest rates to financial stress shock is likely a consequence of conventional monetary policy because central banks tend to decrease their policy rates during periods of financial stress (Baxa et al., 2013). During the financial crisis, central banks used a variety of unconventional measures to support the domestic economy, but according to our results, they also used conventional measures (i.e. decreasing policy interest rates). The maximum impact on interest rates is one year after the shock.

As a robustness check, we estimate identical VAR model but use different aggregation method to generate financial stress index. Instead of principal components, we include 1) equal variance and 2) cumulative density function method one after the other into our VAR. The impulse responses based on these two other methods yield largely similar results to those obtained by the principal components method. In addition, estimate VAR model with GDP growth instead of unemployment. The resulting impulse responses are similar but the confidence intervals for the GDP growth are larger. These results are available upon request.

\section{Concluding Remarks}

The recent financial and economic crisis illustrated the strong relationship between financial stress and economic activity and emphasized the necessity to develop early warning mechanisms. A number of papers have developed financial stress indexes, but only a few have been designed for Central European countries or the Czech Republic. We contribute to this literature by estimating a financial stress index for the Czech Republic and examining the effects on the real economy. The advantage of using a financial stress index is that it combines many underlying financial factors into a simply interpreted and comparable measure, assessing information from various sectors concurrently at any given point in time.

This article compares different methods of assessing financial stress, analysing the Czech economic environment and, subsequently, constructing a financial stress index tailored to the case of the Czech Republic.

Our financial stress index identifies the episode of heightened financial stress during the 2008-2009 period, especially after the fall of Lehman Brothers. Interestingly, the financial stress index decreases to nearly pre-crisis levels soon afterward.

Next, we construct a vector autoregression model of the Czech economy and find that financial stress has systematic effects. Specifically, we find that higher stress is associated with higher unemployment, lower prices and lower interest rates and that the maximum responses of these variables occur approximately one and a half years after the shock to financial stress. This result is robust to the choice of aggregation scheme of our financial stress index. We use three different aggregation methods to generate the index and find that the impulse responses from the vector autogression model are largely similar no matter which financial stress index we use.

In terms of future research, it would be worthwhile to extend the index to include more financial indicators, such as dividends paid, credit default swaps or corporate bonds, 
to test the robustness of this financial stress index. It would also be interesting to examine the forecasting performance of financial stress indexes or to evaluate the effects of financial stress in non-linear and time-varying econometric frameworks.

\section{References}

Adam, T., Benecká, S. (2013). Financial Stress Spillover and Financial Linkages between the Euro Area and the Czech Republic. Czech Journal of Economics and Finance - Finance $a$ úvěr, 63(1), 46-64. Available at: http://journal.fsv.cuni.cz/storage/1265_46-64---_adam.pdf

Aizenman, J., Pasricha, K. G. (2012). Determinants of Financial Stress and Recovery during the Great Recession. International Journal of Finance \& Economics, 17(4), 347-372, http://dx.doi.org/10.1002/ijfe.1457

Babecký, J., Havránek, T., Matějů, J., Rusnák, M., Šmídková, K., Vašíček, B. (2014). Banking, Debt and Currency Crises: Early Warning Indicators for Developed Countries. Journal of Financial Stability, 15(C), 1-17, http://dx.doi.org/10.1016/j.jfs.2014.07.001

Baxa, J., Horváth, R., Vašíček, B. (2013). Time-Varying Monetary-Policy Rules and Financial Stress: Does Financial Instability Matter for Monetary Policy? Journal of Financial Stability, 9(1), 117-138, http://dx.doi.org/10.1016/j.jfs.2011.10.002

Blaschke, W., Jones, M. T., Majnoni, G., Peria, S. M. (2001). Stress Testing of Financial Systems: an Overview of Issues, Methodologies, and FSAP Experiences. International Monetary Fund Working Paper, Washington DC.

Borio, C., Drehman, M., Gambacorta, L., Jiménez, G., Trucharte, C. (2010). Countercyclical Capital Buffers: Exploring Options. BIS Working Papers No 317.

Borys, M. M., Horváth, R., Franta, M. (2009). The Effects of Monetary Policy in the Czech Republic: An Empirical Study. Empirica, 36(4), 419-443, http://dx.doi.org/10.1007/ s10663-009-9102-y

Cardarelli, R., Elekdag, S., Lall, S. (2011). Financial Stress and Economic Contractions. Journal of Financial Stability, 7(2), 78-97, http://dx.doi.org/10.1016/j.jfs.2010.01.005

Cevik, I. E., Dibooglu, S., Kutan, M. A. (2013). Measuring Financial Stress in Transition Economies. Journal of Financial Stability, 9(4), 597-611, http://dx.doi.org/10.1016/j.jfs.2012.10.001

Geršl, A., Heřmánek, J. (2006). Financial Stability Indicators: Advantages and Disadvantages of their Use in the Assessment of the Financial System Stability. CNB - Financial Stability Review, 69-79. Available at: http://www.cnb.cz/en/financial_stability/fs_reports/fsr_2006/ FSR_2006_article_2.pdf

Grimaldi, M. (2010). Detecting and Interpreting Financial Stress in the Euro Area. The European Central Bank Working Paper Series, No. 1214.

Hakkio, S. C., Keeton, W. R. (2009). Financial Stress: What Is It, How Can It Be Measured, and What Does It Matter? Federal Reserve Bank of Kansas City Economic Review, Second Quarter 2009.

Havránek, T., Horváth, R., Matějů. J. (2012). Monetary Transmission and the Financial Sector in the Czech Republic. Economic Change and Restructuring, 45(3), 135-155, http://dx.doi. org/10.1007/s10644-011-9106-z

Hilbers P., Johnsen G., Otker-Robe I., Pazarbasioglu C. (2005). Assessing and Managing Rapid Credit Growth and the Role of Supervisory and Prudential Policies. IMF Working Paper, Monetary and Financial Systems Department, 10.

Hodrick J. R., Prescott C. E. (1997). Postwar U.S. Business Cycles: An Empirical Investigation. Journal of Money, Credit and Banking, 29(1), 1-16, http://dx.doi.org/10.2307/2953682 
Holló, D., Kremer, M., Duca, M. (2012). CISS - A Composite Indicator of Systemic Stress in the Financial Sector. ECB Working Paper Series, No. 1426.

Horváth, R. (2009). The Determinants of the Interest Rate Margins of Czech Banks. Czech Journal of Economics and Finance - Finance a úvěr, 59(2), 128-136. Available at: http://journal.fsv. cuni.cz/storage/1154_1154_horvath.pdf

Illing, M., Liu, Y. (2006). Measuring Financial Stress in a Developed Country:

An Application to Canada. Journal of Financial Stability, 2(3), 243-265, http://dx.doi. org/10.1016/j.jfs.2006.06.002

Islami, M., Kurz-Kim, J. (2013). A Single Composite Financial Stress Indicator and its Real Impact in the Euro Area. Discussion Paper of Deutsche Bundesbank, No. 31/2013.

Jakubík, P., Teplý, P. (2011). The JT Index as an Indicator of Financial Stability of Corporate Sector. Prague Economic Papers, 20(2), pp. 157-176, http://dx.doi.org/10.18267/j.pep.394

Krzak, M., Poniatowski, G., Wasik, K. (2014). Measuring Financial Stress Index and Economic Sensitivity in CEE Countries. CASE Network Research Project, No. 117/2014.

Li, F., St-Amant, P. (2010). Financial Stress, Monetary Policy, and Economic Activity. Bank of Canada, Working Paper.

Louzis, D. P., Vouldis, A. T. (2013). A Financial Systemic Stress Index for Greece. The European Central Bank, Working Paper Series No. 1563.

Lütkepohl, H. (2005). New Introduction to Multiple Time Series Analysis. Springer-Verlag Berlin Heidelberg. ISBN 3-540-40172-5.

Moghadam, R., Viñals, J. (2012). Czech Republic: Financial System Stability Assessment Update. IMF Report No. 12/177.

Oet, V. M., Eiben, R., Bianco, T., Gramlich, D., Ong, J. S. (2011). The Financial Stress Index: Identification of Systemic Risk Conditions. Federal Reserve Bank of Cleveland, Working Paper.

Sims, C. A., J. H. Stock, Watson M. W. (1990). Inference in Linear Time Series Models with Some Unit Roots. Econometrica, 58(1), 113-44, http://dx.doi.org/10.2307/2938337

Sinenko, A., Titarenko, D., Arinš, M. (2013). The Latvian Financial Stress Index as an Important Element of the Financial System Stability Monitoring Framework. Baltic Journal of Economics, 13(2), 85-110, http://dx.doi.org/10.1080/1406099x.2013.10840534

Stock, H. J., Watson, W. M. (1989). New Indexes of Coincident and Leading Economic Indicators, NBER Macroeconomic Annual, 4, 351-409, http://dx.doi.org/10.1086/654119

Stock, H. J., Watson, W. M. (2001). Vector Autoregressions. Journal of Economic Perspectives, 15(4), 101-115, http://dx.doi.org/10.1257/jep.15.4.101

Šimáček, M. (2012). Indexy finančního stresu pro Českou Republiku a Madarsko. Politická Ekonomie, 60(5), 614-634, http://dx.doi.org/10.18267/j.polek.866

Vermeulen, R., Hoeberichts, M., Vašíček, B., Žigraiová, D., Šmídková, K., de Haan, J. (2015). Financial Stress Indices and Financial Crises, Open Economies Review, 26(3), 383-406, http://dx.doi.org/10.1007/s11079-015-9348-x 